\title{
Evaluasi Kesesuaian Lahan Kualitatif dan Kuantitatif Pertanaman Jagung (Zea mays L.) di Laboratorium Lapang Terpadu Fakultas Pertanian Universitas Lampung
}

\author{
Tri Fitriani, Tamaluddin Syam \& Kuswanta F. Hidayat \\ Jurusan Agroteknologi Fakultas Pertanian Universitas Lampung \\ Jl. Prof Soemantri Brodjonegoro No. 1 Bandar Lampung 35143 \\ Email: Fitrii2011@gmail.com
}

\begin{abstract}
ABSTRAK
Produksi jagung di Indonesia belum dapat memenuhi kebutuhan dalam negeri. Salah satu faktor penyebabnya adalah produktivitas yang masih rendah. Diperlukan pengetahuan mengenai evaluasi lahan baik secara fisik (kualitatif) maupun ekonomi (kuantitatif). Penelitian dilaksanakan pada 5 unit lahan pertanaman jagung di Laboratorium Lapang Terpadu Fakultas Pertanian Universitas Lampung seluas 6,784 ha. Penanaman dilakukan pada petak kecil berukuran $2 \times 3 \mathrm{~m}$ dengan 2 kali ulangan. Analisis tanah dilakukan di Laboratorium Ilmu Tanah Fakultas Pertanian Universitas Lampung. Tujuan penelitian mengevaluasi kesesuaian lahan kualitatif pertanaman jagung (Zea mays L.) di Laboratorium Lapang Terpadu Fakultas Pertanian Universitas Lampung, berdasarkan kriteria Djaenudin dkk. (2003) dan mengevaluasi kesesuaian lahan kuantitatif dengan cara menghitung tingkat kelayakan finansial budidaya tanaman jagung (Zea mays L.) di Laboratorium Lapang Terpadu Fakultas Pertanian Universitas Lampung. Hasil penelitian menunjukkan bahwa pada Unit lahan 1 dan 2 cukup sesuai dengan faktor pembatas kejenuhan basa (S2nr), Unit lahan 3 cukup sesuai dengan faktor pembatas kejenuhan basa, lereng, sehingga dapat menyebabkan ancaman erosi (S2nr.eh), Unit lahan 4 sesuai marginal dengan faktor pembatas lereng sehingga dapat menyebabkan ancaman erosi (S3eh), dan Unit lahan 5 tidak sesuai dengan faktor pembatas lereng dan ancaman erosi (Neh). Unit lahan 1,2,3, 4, dan 5 secara finansial meguntungkan, hal ini dibuktikan dari hasil perhitungan yang menunjukkan bahwa nilai $\mathrm{R} / \mathrm{C}>1$.
\end{abstract}

Kata kunci: jagung, kelayakan finansial, kesesuaian lahan, kualitatif, kuantitatif.

\section{PENDAHULUAN}

Tanaman jagung di Indonesia merupakan salah satu tanaman pangan terpenting kedua setelah padi. Tanaman jagung dianggap penting karena dapat dijadikan sebagai bahan pangan, pakan ternak, bahan baku industri, minuman, dan lain-lain. Sentra produksi jagung terbesar di Indonesia berada di Pulau Jawa yakni Provinsi Jawa Timur menghasilkan 5.737.382 ton dan Jawa Tengah menghasilkan 3.051.516 ton pada tahun 2014. Pulau Sumatera juga merupakan penghasil jagung, salah satunya Provinsi Lampung dengan hasil 1.719.386 ton pada tahun 2014. Secara keseluruhan produksi jagung Indonesia mencapai 19.008.426 ton pada tahun 2014 (Badan Pusat Statistik, 2014).

Produksi jagung di Indonesia belum dapat memenuhi kebutuhan dalam negeri. Salah satu faktor penyebabnya adalah produktivitas jagung di Indonesia yang masih rendah, yaitu 4,954 ton/ha dan produktivitas jagung di Provinsi Lampung, yaitu 5,074 ton/ha (Badan Pusat Statistik, 2014). Salah satu cara untuk meningkatkan produksi jagung adalah dengan mengetahui kondisi lahan yang akan digunakan layak atau tidak untuk pertanaman jagung. Untuk mengetahui kelayakan lahan tersebut, maka perlu dilakukan evaluasi kesesuaian lahan.

Evaluasi lahan merupakan salah satu penilaian penampilan potensi lahan untuk tujuan tertentu. Kegiatan evaluasi lahan salah satunya dapat berupa klasifikasi kesesuaian lahan. Pelaksanaan evaluasi lahan mempertimbangkan semua aspek yang menjadi pembatas dalam penggunaan lahan yang ditetapkan agar lahan dapat digunakan secara optimal (Mahi, 2013).

Evaluasi kesesuian lahan pada dasarnya berhubungan dengan evaluasi untuk suatu penggunaan tertentu, seperti untuk budidaya padi, jagung, palawija, dan sebagainya. Kemampuan lahan umumnya ditujukan untuk penggunaan yang lebih luas atau lebih umum, seperti penggunaan pertanian, industri, jasa, perkotaan, permukiman, dan sebagainya (Sitorus, 1985). Kesesuaian lahan dibagi menjadi dua, yaitu kesesuaian kualitatif dan kantitatif. Pada penelitian ini, kesesuaian lahan kualitatif dilakukan dengan membandingkan karakteristik kelas kesesuaian lahan Djaenudin dkk. 
(2003), dengan karakteristik kesesuaian lahan pemilik, sedangkan kesesuaian lahan kuantitatif, yaitu menganalisis kelayakan finansial pada pertanaman jagung.

\section{BAHAN DAN METODE}

Penelitian ini dilaksanakan di Laboratorium Lapang Terpadu Fakultas Pertanian Universitas Lampung pada bulan Mei-Agustus 2015 di 5 unit lahan pertanaman jagung (Zea mays L.) dan analisis tanah dilakukan di Laboratorium Ilmu Tanah Jurusan Agroteknologi Fakultas Pertanian Universitas Lampung. Pengambilan sampel tanah dilakukan secara proposional dari kelima unit lahan.

Penelitian ini dilakukan dengan menggunakan metode survei dengan pendekatan evaluasi lahan secara paralel, yaitu melakukan evaluasi kualitatif dan kuantitatif secara bersamaan berdasarkan kriteria fisik Djaenuddin dkk. (2003) dan analisis kelayakan finansial tanaman jagung (Zea mays L.) dengan menilai Net Revenue Cost Rasio (Net R/C). Pelaksanaan survei dilakukan dengan beberapa tahap, yaitu tahap persiapan, pengumpulan data, dan analisis data.

Tahap persiapan merupakan tahap studi pustaka tentang keadaan umum lokasi penelitian sehingga diperoleh gambaran umum tentang lokasi penelitian, seperti pembuatan surat izin penelitian, data iklim, peta lokasi, karakteristik lahan. Dalam penelitian ini dilakukan penanaman jagung pada 5 unit lahan, jagung ditanam pada petak kecil dengan ukuran $2 \times 3$ myang dilakukan 2 kali ulangan pada setiap unit lahan dengan jarak tanam $20 \times 70 \mathrm{~cm}$. Penanaman jagung dilakukan untuk mengevaluasi kecocokkan antara lahan Laboratorium Lapang Terpadu dengan syarat tumbuh tanaman jagung.

Data yang dikumpulkan meliputi data fisik (primer dan sekunder) dan data ekonomi (primer). Pengumpulan data fisik primer yang dikumpulkan meliputi data karakteristik lahan, yaitu : drainase, bahan kasar, kedalaman tanah, ancaman erosi, bahaya sulfidik, toksisitas, alkalinitas, bahaya banjir, lereng, batuan permukaan, dan batuan singkapan. Data yang di analisis di laboratorium yaitu : KTK tanah, basa-basa dapat ditukar ( $\mathrm{Ca}, \mathrm{Mg}, \mathrm{Na}$, dan $\mathrm{K}$ ), $\mathrm{pH}$ tanah, C-Organik, dan tekstur tanah. Pengumpulan data fisik sekunder meliputi data curah hujan selama 5 tahun terakhir. Data dikumpulkan dengan cara mengambil dari Badan Meteorologi dan Geofisika Stasiun Klimatologi Masgar Lampung, Kabupaten Lampung Selatan. Data sosial ekonomi yang dikumpulkan sebagai data primer meliputi biaya tetap, yaitu sewa lahan. Biaya variabel, yaitu biaya produksi (benih, pupuk), peralatan, tenaga kerja (pengolahan tanah, penanaman, penyiraman, pemupukan, pengendalian hama penyakit, panen, dan lain-lain), dan pendapatan yang diperoleh. Data sosial ekonomi yang dikumpulkan sebagai data sekunder, yaitu data luas panen dan produksi tanaman jagung di provinsi Lampung.

Prinsip pengambilan contoh tanah adalah pengambilan sampel harus mewakili daerah yang diteliti. Pengambilan sampel tanah dilakukan secara komposit pada 5 unit lahan, pengambilan sampel tanah menggunakan teknik sampling tanah dengan metode pendekatan satuan lahan atau unit lahan. Contoh tanah diambil menggunakan bor dengan 15 titik pengambilan sampel, kemudian contoh tanah yang sudah diambil dari 5 unit lahan dikering anginkan, lalu diayak dengan menggunakan ayakan $2 \mathrm{~mm}$, kemudian sampel tanah akan dianalisis di Laboratorium Ilmu Tanah Fakultas Pertanian Universitas Lampung, untuk mengetahui sifat kimia dan fisiknya.

Analisis kesesuaian lahan kualitatif dilakukan dengan cara mencocokkan syarat tumbuh tanaman jagung berdasarakan kriteria Djaenudin dkk. (2003) dengan menilai karakteristik dan kualitas lahan di lapang. Analisis kuantitatif dilakukan analisis finansial menghitung nilai $R / C$ ratio dengan satuan hektar (Soekartawi, 1995).

\section{HASIL DAN PEMBAHASAN}

Penilaian kesesuaian lahan kualitatif berdasarkan kriteria biofisik untuk tanaman jagung didasarkan pada kualitas dan karakteristik lahan yang berada di Laboratorium Lapang Terpadu Fakultas Pertanian Universitas Lampung yang dibandingkan dengan persyaratan tumbuh tanaman jagung berdasarkan kriteria Djaenudin dkk. (2003). Berdasarkan hasil pengamatan dan pengukuran karakteristik lahan maka kelas kesesuaian lahan untuk tanaman jagungdi lokasi penelitian pada Unit lahan 1-5 (Tabel 1).

Berdasarkan hasil pengamatan dan karakteristik lahan seperti tertera pada Tabel 1, maka didapat kelas kesesuaian lahan pertanaman jagung (Zea mays L.). Berdasarkan pendekatan unit lahan dari 5 unit lahan di Laboratorium Lapang Terpadu FP Unila menurut Djaenudin dkk. (2003) pada Unit lahan 1 dan 2 cukup sesuai dengan faktor pembatas kejenuhan basa (S2nr), Unit lahan 3 cukup sesuai dengan faktor pembatas kejenuhan basa, lereng, dan ancaman erosi (S2nreh), Unit lahan 4 sesuai marginal dengan faktor pembatas lereng dan ancaman erosi (S3eh), dan pada Unit lahan 5 tidak sesuai dengan faktor pembatas lereng dan ancaman erosi (Neh). 


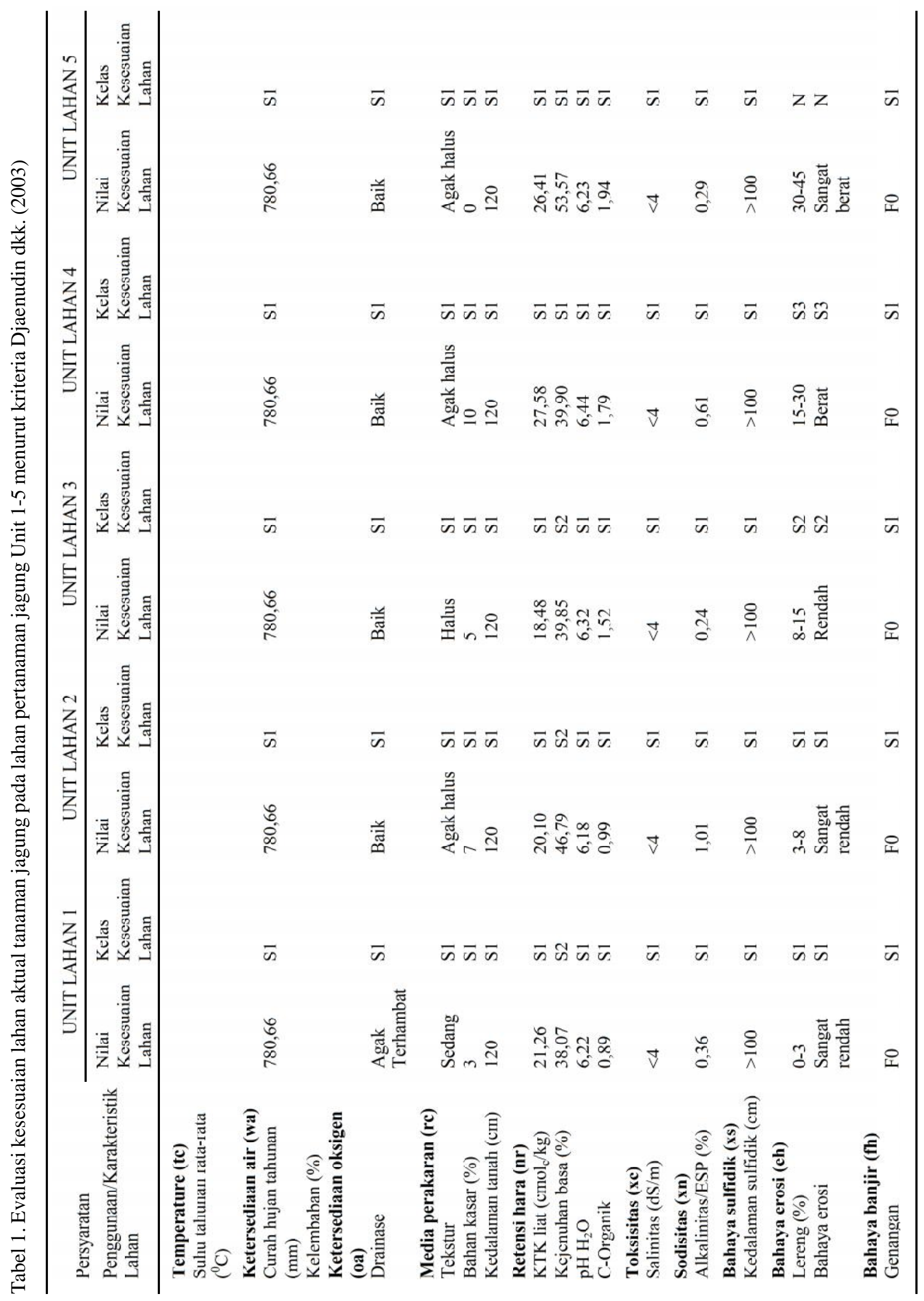


Biaya usaha tani tanaman jagung (Zea mays L.) terdiri dari biaya tetap dan biaya variabel. Biaya tetap merupakan biaya yang tidak dipengaruhi oleh naik turunnya produksi yang dihasilkan, sedangkan biaya variabel merupakan biaya produksi yang besar kecilnya biaya ini mempengaruhi besar kecilnya jumlah produksi. Biaya yang dikeluarkan untuk budidaya jagung seluas 1 hektar sebesar Rp 8.309.765,00.

Produksi jagung pada Unit lahan 1 mendapatkan hasil sebesar 4,005 ton/ha, pada Unit lahan 2 mendapatkan hasil sebesar 6,962 ton/ha, Unit lahan 3 mendapatkan hasil sebesar 6,993 ton/ha, Unit lahan 4 mendapatkan hasil sebesar 7,845 ton/ha, dan pada Unit lahan 5 mendapatkan hasil sebesar 10,027 ton/ha. Penerimaan yang diperoleh dari hasil penjualan jagung pipilan kering, pada Unit lahan 1 yaitu sebesar Rp. 12.015.00,00, pada Unit lahan 2 yaitu sebesar Rp. 20.886.000,00, pada Unit lahan 3 yaitu sebesar Rp. 20.979.000,00, pada Unit lahan 4 yaitu sebesar Rp. 23.535.000,00 dan pada Unit lahan 5 yaitu sebesar Rp. $30.081,00$.

Analisis finansial dilakukan dengan menghitung penerimaan bersih sekarang, nilai perbandingan antara penerimaan dan biaya. Nilai $\mathrm{R} / \mathrm{C}$ pada Unit lahan 1 sebesar 1,44, nilai $\mathrm{R} / \mathrm{C}$ pada Unit lahan 2 sebesar 2,51, nilai $\mathrm{R} / \mathrm{C}$ pada Unit lahan 3 sebesar 2,52, nilai $\mathrm{R} / \mathrm{C}$ pada Unit lahan 4 sebesar 2,83, dan nilai R/C pada Unit lahan 5 sebesar 3,61.

Berdasarkan hasil penelitian yang telah dilakukan pada lahan budidaya tanaman jagung baik secara langsung dilapang maupun analisis di Laboratorium, setelah dicocokkan berdasarkan kriteria Djaenudin dkk. (2003), pada setiap unit lahan memiliki faktor pembatas yang berbeda-beda. Pada Unit lahan 1 memiliki faktor pembatas kejenuhan basa sebesar 38,07\% (S2nr), Unit lahan 2 dengan faktor pembatas kejenuhan basa sebesar 46,79\% (S2nr), Unit lahan 3 dengan faktor pembatas kejenuhan basa sebesar 39,85\% (S2nr), lereng 8-15\%, dan ancaman erosi rendah (S2eh), Unit lahan 4 memiliki faktor pembatas lereng $15-30 \%$ dan ancaman erosi berat (S3eh), dan Unit lahan 5 memiliki faktor pembatas lereng 30-45\% dan ancaman erosi sangat berat (Neh).

Upaya yang dapat dilakukan untuk meningkatkan kejenuhan basa (KB) dalam tanah menurut Noza dkk. (2014), dengan cara pemberian kapur dapat memperbaiki sifat kimia tanah salah satunya yaitu meningkatkan kejenuhan basa. Upaya lain yang dapat dilakukan untuk meningkatkan kejenuhan basa (KB) menurut Roidah (2013), dengan penambahan bahan organik yang didapat dari pemupukan. Pupuk yang diberikan yaitu baik pupuk kandang, pupuk hijau dan pupuk kompos. Pemberian pupuk yang sesuai dapat meningkatkan kesuburan tanah dan produksi tanaman menjadi relatif stabil serta melengkapi persediaan unsur hara di dalam tanah, sehingga kebutuhan tanaman terpenuhi dan tercapai daya hasil (produksi) yang maksimal.

Berdasarkan hasil pengamatan langsung di lapang, pada Unit lahan 3 memiliki tingkat kelerengan 8-15\% yang masuk dalam kelas kesesuaian lahan cukup sesuai (S2), Unit lahan 4 tingkat kelerengan 15-30\% yang masuk dalam kelas kesesuaian lahan sesuai marginal (S3), dan Unit lahan 5 tingkat kelerengan 30-45\% yang masuk kedalam kelas kesesuaian lahan tidak sesuai (N). Menurut Hardjowigeno (2007), kemiringan lereng yang tinggi akan meyebabkan terjadinya aliran permukaan yang besar. Untuk itu, upaya yang perlu dilakukan yaitu perlu adanya konservasi tanah dengan cara pembuatan teras bangku atau teras tangga pada lereng 30-45\%. Menurut Sinukaban dan Adnyana (2007), dengan tingkat lereng 8-15\% dapat dilakukan penanggulangan dengan cara penanaman dalam strip rumpu vetiver yang dikenal dengan nama akar wangi dan sistem pengelolaan sisa tanaman. Menurut Banuwa (2013), untuk memperbaiki lereng $15-30 \%$ dapat dilakukan penanaman diatas guludan memotong arah lereng (mengikuti kontur).

Untuk mengetahui tingkat kelayakan usahatani jagung di lahan penelitian, digunakan analisis R/C Ratio, dimana nilai $\mathrm{R} / \mathrm{C}$ Ratio adalah perbandingan atau nisbah antara penerimaan dan biaya. Bila nilai $\mathrm{R} / \mathrm{C}=1$ artinya usaha dalam keadaan tidak untung dan tidak rugi, bila R/C >1, maka usaha delam keadaan yang menguntungkan, tetapi apabila nilai $\mathrm{R} / \mathrm{C}<1$ maka usaha mengalami kerugian (Soekartawi, 1995).

Hasil pengolahan data menunjukkan bahwa pada Unit lahan 1 penerimaan yang didapat sebesar $\mathrm{Rp}$ 12.015.000,00 dan pengeluaran sebesar Rp 8.309.765,00 sehingga didapat nilai R/C 1,44 yang artinya usahatani jagung di Unit lahan 1 menguntungkan. Pada Unit lahan 2 penerimaan yang didapat sebesar Rp 20.886.000,00 dan pengeluaran sebesar Rp 8.309.765,00 sehingga didapat nilai R/C 2,51 yang artinya usahatani jagung di Unit lahan 2 menguntungkan, Unit lahan 3 penerimaan yang didapat sebesar $\mathrm{Rp} 20.979 .000,00$ dan pengeluaran sebesar Rp 8.309.765,00 sehingga didapat nilai R/C 2,52 yang artinya usahatani jagung di Unit lahan 3 menguntungkan, Unit lahan 4 penerimaan yang didapat sebesar Rp 23.535.000,00 dan pengeluaran sebesar Rp 8.309.765,00 sehingga didapat nilai R/C 2,83 yang artinya usahatani jagung di Unit lahan 4 menguntungkan, dan Unit lahan 5 penerimaan yang didapat sebesar Rp 30.081.000,00 dan pengeluaran sebesar Rp 8.309.765,00 sehingga nilai $\mathrm{R} / \mathrm{C}$ yang didapat 3,61 yang artinya usahatani jagung di Unit lahan 5 menguntungkan. 
Berdasarkan hasil analisis tanah dan pengamatan langsung dilapang, pada lahan penelitian Unit 1 memiliki tingkat kelerengan yang sangat sesuai dengan ancaman erosi yang rendah akan tetapi produksi rendah. Terdapat beberapa faktor yang mempengaruhi, yaitu hasil analisis tanah menunjukkan bahwa nilai unsur hara Unit lahan 1 lebih rendah dibandingkan Unit lahan lainnya. Selain itu, setelah tanaman jagung berumur 30 HST pertumbuhan mulai terhambat, tanaman menjadi kerdil, batang dan daun berwarna kekuningan seperti kekurangan unsur hara N,P, dan K. Menurut Isrun (2009), salah satu upaya yang dapat dilakukan untuk meningkatkan unsur hara $\mathrm{N}, \mathrm{P}$ dan $\mathrm{K}$ dalam tanah yaitu dengan pemberian bahan organik berupa pupuk cair organik dapat memperbaiki sifat kimia (ketersediaan $\mathrm{N}$, $\mathrm{P}, \mathrm{K}$ ) dan dapat meningkatkan produksi jagung. Pada Unit lahan 1 memiliki drainase agak terhambat menurut Effendy (2011), perlu dilakukan perbaikan dengan pembuatan saluran drainase. Menurut Hardjowigeno (2007), perlu penambahan bahan organik untuk memperbaiki struktur tanah. Dapat diasumikan setelah dilakukan perbaikan pada Unit lahan 1 produksi dapat meningkat untuk musim tanam selanjutnya.

Hasil pengamatan pada Unit lahan 3 memiliki tingkat kelerengan 8-15\% yang termasuk dalam kelas kesesuaian lahan cukup sesuai tidak mempengaruhi produksi jagung. Perlu dilakukan penanggulangan untuk mencapai tingkat kelerengan $<8$ yang termasuk dalam kelas kesesuaian lahan sangat sesuai sehingga dapat mempertahankan atau meningkatkan produksi. Menurut Sinukaban dan Adnyana (2007), salah satu cara yang dapat dilakukan, yaitu dengan melakukan penanaman strip rumput vetiver (Vetiveria zizanioides) yang dikenal dengan nama akar wangi dan sistem pengelolaan sisa tanaman pada lahan dengan tingkat kelerengan 7-14\% untuk mencegah terjadinya erosi. Berdasarkan hasil penelitian yang telah dilakukan pada tanaman kacang tanah dan jagung, dengan penanaman strip rumput vetiver dapat menurunkan aliran permukaan sebesar $24,6 \%$ dan dapat menurunkan erosi sebesar $34,2 \%$. Penanggulangan dengan sistem pengelolaan sisa tanaman dengan pemakaian jerami sebagai mulsa dapat menurunkan aliran permukaan sebesar $74,9 \%$ dan erosi dapat ditekan sebesar 96,1\%.

Hasil pengamatan pada Unit lahan 4 memiliki tingkat kelerengan 15-30\% yang masuk dalam kelas kesesuaian lahan sesuai marginal tidak mempengaruhi produksi jagung. Perlu dilakukan pencegahan atau memperkecil terjadinya erosi sehingga dapat mempertahankan atau meningkatkan produksi. Menurut Arsyad (2010), salah satu cara yang dapat memperbaiki lahan dengan kemiringan lereng 15-30\%, yaitu dengan cara pembuatan rorak. Rorak merupakan lubang yang digali kedalam tanah dengan ukuran tinggi $60 \mathrm{~cm}$ dan lebar $50 \mathrm{~cm}$ dengan panjang berkisar $1-5 \mathrm{~m}$. Jarak kesamping antar satu rorak dengan rorak lainnya berkisar 10-15 m, sedangkan jarak searah lereng berkisar 3-5 m. Selain pembuatan rorak, menurut Banuwa (2013), dapat juga dilakukan penanaman pada guludan memotong lereng (mengikuti kontur). Hal ini dibuktikan dari hasil penelitian Sinukaban dan Banuwa (2007), bahwa dengan melakukan penanaman diatas guludan memotong arah lereng (mengikuti kontur) mampu menekan aliran permukaan sebesar $71,4 \%$ dan menekan erosi sebesar $87,3 \%$.

Hasil analisis tanah dan pengamatan secara langsung dilapang menunjukkan bahwa pada Unit lahan 5 memiliki tingkat kelerengan yang tidak sesuai yang dapat menyebabkan ancaman erosi sangat berat, tetapi produksi jagung lebih tinggi dibandingkan dengan unit lahan lainnya. Terdapat beberapa faktor yang mempengaruhi, yaitu unsur hara dalam tanah pada Unit lahan 5 lebih tinggi dibandingkan dengan unit lahan lainnya, hal ini disebabkan pada Unit lahan 5 sebelumnya tidak pernah digunakan untuk budidaya. Menurut Hardjowigeno (2007), salah satu cara yang dapat dilakukan untuk memperbaiki tingkat kelerengan tidak sesuai yang dapat menyebabkan ancaman erosi sangat berat, yaitu dengan melakukan konservasi tanah dengan pembuatan teras bangku atau teras tangga. Penanggulangan dengan cara teras bangku atau teras tangga, menyebabkan tanah-tanah sub soil (tanah yang tidak subur) kepermukaan, maka perlu pemberian pupuk organik. Fungsi pupuk organik dapat memperbaiki struktur tanah, sumber unsur hara N, P, S, menambah kemampuan tanah untuk menahan unsur-unsur hara (Kapasitas Tukar Kation tanah menjadi tinggi), dan sebagai sumber energi bagi organisme.

\section{KESIMPULAN}

Berdasarkan hasil penelitian dapat disimpulkan bahwa kelas kesesuaian lahan pertanaman jagung (Zea mays L.) berdasarkan pendekatan unit lahan dari 5 unit lahan di Laboratorium Lapang Terpadu FP Unila menurut Djaenudin dkk. (2003) pada Unit lahan 1 dan 2 cukup sesuai dengan faktor pembatas kejenuhan basa (S2nr), Unit lahan 3 cukup sesuai dengan faktor pembatas kejenuhan basa, lereng, dan ancaman erosi (S2nr.eh), Unit lahan 4 sesuai marginal dengan faktor pembatas lereng dan ancaman erosi (S3eh), dan pada Unit lahan 5 tidak sesuai dengan faktor pembatas lereng dan ancaman erosi (Neh). Usaha budidaya tanaman jagung (Zea mays L.) di Laboratorium Lapang Terpadu FP Unila 
secara finansial menguntungkan dan layak untuk dilanjutkan pada Unit lahan 1,2,3,4, dan 5, hal ini dibuktikan dari hasil perhitungan yang menunjukkan bahwa nilai R/C pada Unit lahan 1 sebesar 1,44, nilai R/ $\mathrm{C}$ pada Unit lahan 2 sebesar 2,51, nilai $\mathrm{R} / \mathrm{C}$ pada Unit lahan 3 sebesar 2,52, nilai R/C pada Unit lahan 4 sebesar 2,83, dan nilai $\mathrm{R} / \mathrm{C}$ pada Unit lahan 5 sebesar 3,61.

\section{DAFTAR PUSTAKA}

Arsyad, S. 2010. Konservasi Tanah dan Air. IPB Press. Bogor. 472 hlm.

Badan Pusat Statistik. 2014. Tanaman Pangan Produksi Tanaman Jagung Provinsi Lampung. Tersedia: http://bps.go.id/tnmn_pgn.php?kat=3., [5 Oktober 2014].

Banuwa, I.S. 2013. Erosi. Kencana Prenada Media Group. Jakarta. $204 \mathrm{hlm}$.

Djaenudin, D., H. Marwan, H. Subagyo, dan A. Hidayat. 2003. Petunjuk Teknis Evaluasi Lahan untuk Komoditas Pertanian. Departemen Pertanian. $154 \mathrm{hlm}$.

Effendy. 2011. Drainase untuk meningkatkan kesuburan tanah. Jurnal Pilar 6(2): 179-188.

Hardjowigeno, S. 2007. Ilmu Tanah. CV Akademika Pressindo. Jakarta. $288 \mathrm{hlm}$.

Isrun. 2009. Perubahan status N, P, K tanah dan hasil tanaman jagung akibat pemberian pupuk cair organik. Jurnal Agroland 16(4): 281-285.
Mahi, A. K. 2013. Survei Tanah, Evaluasi dan Perencanaa Penggunaan Lahan. Lembaga Penelitian Universitas Lampung. Bandar Lampung. $220 \mathrm{hlm}$.

Noza, L., H. Yetti, dan M. A. Khoiri. 2014. Pengaruh pemberian kapur terhadap sifat kimia tanah. Jurnal Faperta 1(2): 68-79.

Roidah, I. S. 2013. Manfaat penggunaan pupuk organik untuk kesuburan tanah. Jurnal Zootek 1(1): 3042.

Sinukaban, N., dan I. W. S. Adnyana. 2007. Pengaruh strip rumput vetiver dan sistem pengelolaan sisa tanaman terhadap aliran permukaan, erosi, dan produktivitas tanah. Konservasi Tanah dan Air. Direktorat Jenderal RLPS. IPB Bogor. 61-77 hlm.

Sinukaban, N., dan I. S. Banuwa. 2007. Pengaruh tindakan konservasi tanah terhadap aliran permukaan, erosi, dan kehilangan hara pada pertanaman sayuran. Konservasi Tanah dan Air. Direktorat Jenderal RLPS. IPB Bogor. HIm 183196.

Sitorus, S. R. P. 1985. Evaluasi Sumber Daya Lahan. Tarsito. Bandung. $185 \mathrm{hlm}$.

Soekartawi. 1995. Analisis Usaha Tani. UI. Press. Jakarta. 108 hlm. 